\title{
Science on film
}

\section{As worldwide festivals attest, science can look good on celluloid.}

Name a good science film. That is, a good film in which good (correct) science is central to the plot, or a least has a strong supporting part. Perhaps the protagonist (hero or villain) is also a scientist. If you don't allow the genre of science fiction, it's not that easy. When this challenge was issued in the Nature Physics office, there were frowns, thoughtful pauses, some googling, and only then a few suggestions.

Of course the line between fiction involving science and science fiction is a blurred one (and each of us probably has our own definition of where the 'SF' genre begins). But there have been successful films that take real science as their imaginative springboard and keep it central to the plot: Contact, for example, written by Carl Sagan and starring Jodie Foster as a radioastronomer engaged in the search for extraterrestrial intelligence; and Gattaca, by Andrew Niccol, in which the level of 'perfection' of an individual's genetic profile determines their role in society.

\section{The science film 'industry' is growing, and with it the skills of scientists and film-makers, together, in presenting science in film.}

Others put scientists and their personal struggles centre stage, such as the portrayal of mathematician John Nash in Ron Howard's 2001 film A Beautiful Mind, and the newly released Creation, focusing on Charles Darwin's agony over the death of his daughter, the religious conviction of his wife and the implications of his embryonic theory of evolution. The struggle over evolution continues: as Nature Physics went to press, Creation still had no US distributor - the film will be seen around the world but not in the USA, where its subject matter is deemed too unattractively controversial.

Evolution aside, science has many other stories that have the power to grip an audience or launch a line of imaginative thinking. And over the next few months, some of those ideas will feature in a batch of science film festivals worldwide. First up is the Imagine Science Film Festival,

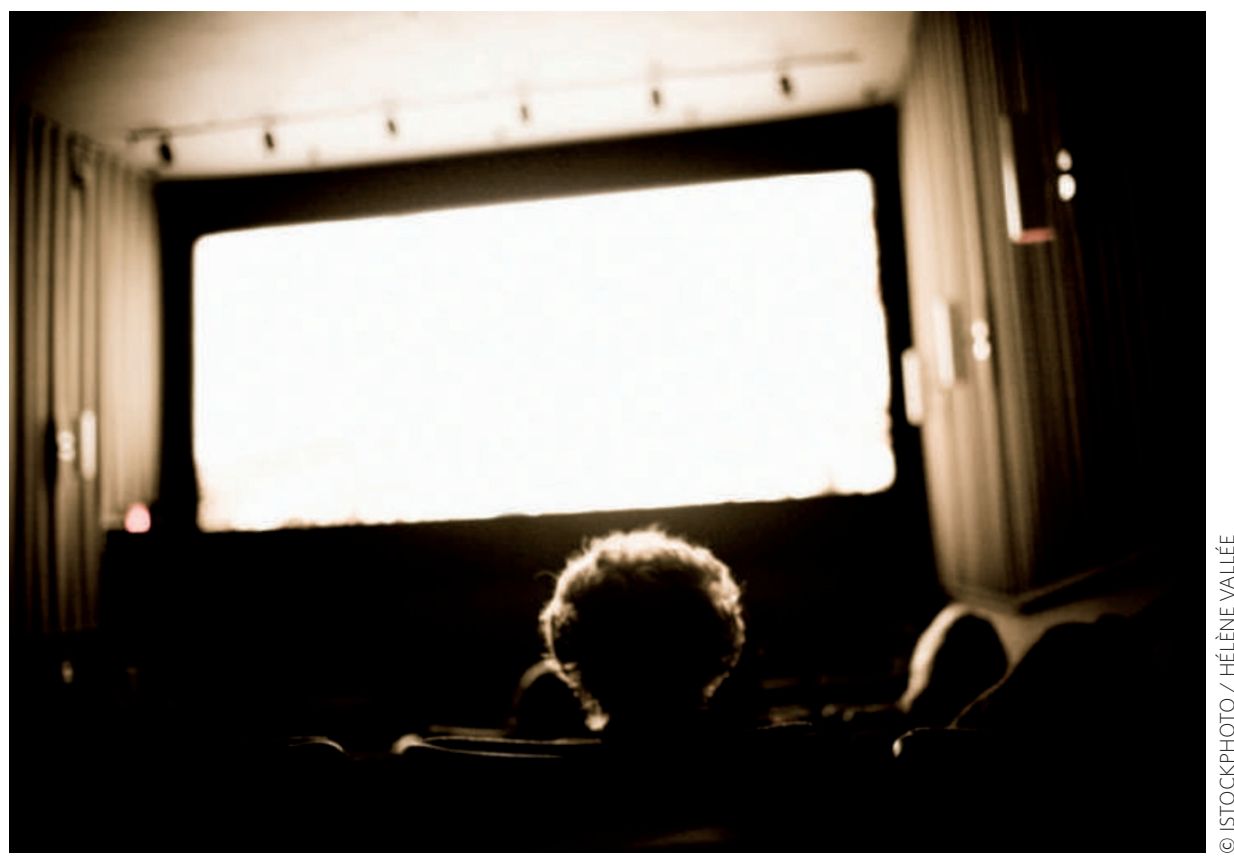

in New York from 15 to 24 October (www.imaginesciencefilms.com). Imagine Science Film is a non-profit organization that aims to encourage "a greater collaboration between scientists who dedicate their lives to studying the world we live in and filmmakers who have the power to interpret and expose this knowledge, ultimately making science accessible and stimulating to a broader audience".

In its second annual outing, the festival includes four feature films and 46 shorts. (Nature sponsors one of the festival awards.) On the programme are Claire Barker's Babbage, distilling the "uncelebrated genius" of the computer inventor, and Decoding Alan Turing from Christopher Racster; a clutch of shorts inspired by the Large Hadron Collider, wormholes and multiverses, another that reveals "the secret lives of magnetic fields"; and an animation by Yaron Bar on what scientists dream about at night. Josh Kameyer's Chances Are follows a hapless maths geek who accidentally spends the $\$ 20$ bill on which a pretty girl wrote her phone number - he must use his knack for calculating probability to track it, and the girl, down.

Festivals across Europe follow, starting with the 4th International Science Film
Festival, in Athens, Greece, from 19 to 26 October (www.caid.gr/isffa). Even more recently founded festivals, although building on the success of their previous years, include, in late November, science film festival $\mathrm{sf}^{2}$ - the European Festival of Educational and Science Films - in Vienna, Austria (www.sciencefilmfest.at/sff), and December's CinémaScience in Bordeaux, France (www.cnrs.fr/cinemascience).

The reach of the science film festival is global. Australia ran its SCINEMA festival across the country in August, in conjunction with its National Science Week. Meanwhile, educational science filmmaking is in the spotlight in November, when Bangkok hosts its Fifth Science Film Festival, organized by the GoetheInstitut, the French Embassy and the Institute for the Promotion of Teaching Science and Technology in Thailand (www.goethe.de/INS/th/prj/wif).

The science film 'industry' is undoubtedly growing, and with it the skills of scientists and film-makers, together, in presenting science in film. Support a science film festival near you, if you can, and look forward to the wider selection of celluloid science (and science fiction) that they have the potential to inspire. 